University of Nebraska - Lincoln

DigitalCommons@University of Nebraska - Lincoln

NASA Publications

National Aeronautics and Space Administration

2013

\title{
Error consistency analysis scheme for infrared ultraspectral sounding retrieval error budget estimation
}

Daniel K. Zhou

NASA Langley Research Center, Hampton, VA

Allen M. Larar

NASA Langley Research Center, Hampton, VA

Xu Liu

NASA Langley Research Center, Hampton, VA

William L. Smith

Hampton University

L. Larrabee Strow

University of Maryland-Baltimore County

Follow this and additional works at: http://digitalcommons.unl.edu/nasapub

Zhou, Daniel K.; Larar, Allen M.; Liu, Xu; Smith, William L.; and Strow, L. Larrabee, "Error consistency analysis scheme for infrared ultraspectral sounding retrieval error budget estimation" (2013). NASA Publications. 204.

http://digitalcommons.unl.edu/nasapub/204

This Article is brought to you for free and open access by the National Aeronautics and Space Administration at DigitalCommons@University of Nebraska - Lincoln. It has been accepted for inclusion in NASA Publications by an authorized administrator of DigitalCommons@University of Nebraska - Lincoln. 


\title{
Error consistency analysis scheme for infrared ultraspectral sounding retrieval error budget estimation
}

\author{
DANIEL K. ZHOU*†, ALLEN M. LARAR $†$, XU LIU $†$, WILLIAM L. SMITH $\ddagger \S$ \\ and L. LARRABEE STROW \\ $\dagger$ NASA Langley Research Center, Hampton, VA 23693, USA \\ $\ddagger$ Department of Atmospheric and Planetary Sciences, Hampton University, Hampton, \\ VA 23668, USA
}

§Space Science and Engineering Center, University of Wisconsin-Madison, Madison, WI 53706, USA

qDepartment of Physics, University of Maryland-Baltimore County, Baltimore, MD

21250, USA

(Received 4 June 2012; in final form 7 August 2012)

\begin{abstract}
Great effort has been devoted towards validating geophysical parameters retrieved from ultraspectral infrared radiances obtained from satellite remote sensors. An error consistency analysis scheme (ECAS), utilizing fast radiative transfer model (RTM) forward and inverse calculations, has been developed to estimate the error budget in terms of mean difference and standard deviation of error in both spectral radiance and retrieval domains. The retrieval error is assessed through ECAS without relying on other independent measurements such as radiosonde data. ECAS establishes a link between the accuracies of radiances and retrieved geophysical parameters. ECAS can be applied to measurements from any ultraspectral instrument and any retrieval scheme with its associated RTM. In this manuscript, ECAS is described and demonstrated with measurements from the MetOp-A satellite Infrared Atmospheric Sounding Interferometer (IASI). This scheme can be used together with other validation methodologies to give a more definitive characterization of the error and/or uncertainty of geophysical parameters retrieved from ultraspectral radiances observed from current and future satellite remote sensors such as IASI, the Atmospheric Infrared Sounder (AIRS), and the Cross-track Infrared Sounder (CrIS).
\end{abstract}

\section{Introduction}

Validation efforts must be devoted towards remotely sensed satellite radiances and retrieved geophysical parameters (i.e. state vector or retrievals) (Tobin et al. 2006, Pougatchev et al. 2009, Larar et al. 2010). For example, Tobin et al. (2006) used a multi-instrument/platform correlative measurement dataset to build the bestestimated atmospheric state for each individual satellite measurement for validation. Pougatchev et al. (2009) developed a linear statistical validation assessment model (VAM) providing the best-estimated atmospheric state and corresponding nominal satellite measurements using the correlative data per se. These state parameter

\footnotetext{
*Corresponding author. Email: daniel.k.zhou@nasa.gov
} 
validation methods are accurate, but they depend on other independent measurements, such as radiosondes, and the accuracy of these independent 'coincident' measurements. These data usually are collected during dedicated field campaigns and/or matchup soundings (e.g. radiosonde and Raman lidar data). In practice, previous validation studies are more complex in considering that 'coincident' measurements or that measurement-derived 'truth' is at the same location and time. In addition, the vertical and horizontal resolutions of other independent measurements have to be taken into account as well. The instrumental averaging kernels (Rodgers 2000, Pougatchev et al. 2009) are typically used to resolve the difference in vertical resolution. However, the difference of horizontal resolution and the effect of spatial variations in atmospheric properties are too complex to consider and are often neglected. Retrieval error analysis for an ensemble of cases is essential, and theoretical discussions were given by Rodgers (2000).

Our aim is to understand and estimate the retrieval error by obtaining a link between the retrieval and radiometric accuracies. The major error sources are from (1) an ill-posed retrieval system, (2) instrument random noise, and (3) 'un-modelled' errors that refer to the statistical discrepancies, in terms of mean difference and standard deviation of error, between the observed radiances and radiative transfer model (RTM) simulated radiances containing instrument random noise. These so-called 'un-modelled' errors include all errors except the instrument random noise; they are mainly the sum of the model parameter error and the forward model error as defined by Rodgers (2000) and the instrumental calibration bias, if there is any. The error consistency analysis scheme (ECAS) gives detailed radiance error budget estimation and provides an 'un-modelled' radiance error as required in most conventional retrieval methods. We would like to answer questions such as how the radiometric random noise in the measurement propagates to the retrieval noise in the retrievals (e.g. temperature and moisture profiles), and what is the magnitude of retrieval error introduced by an ill-posed retrieval model. Section 2 describes a statistical ECAS developed for retrieval error estimation. Initial demonstration is given in Section 3 using measurements from the Infrared Atmospheric Sounding Interferometer (IASI) on the MetOp-A satellite (e.g. Klaes et al. 2007, Hilton et al. 2012) during the Joint Airborne IASI Validation Experiment (JAIVEx) (Zhou et al. 2009, Larar et al. 2010), followed by a discussion in Section 4 and a summary of this work.

\section{Methodologies}

The ECAS is developed through fast RTM forward and inverse calculations (hereafter denoted as $\mathrm{RTM}^{-1}$ ) to estimate the error budget in terms of mean difference (bias) and standard deviation of error (STDE) in both spectral radiance and retrieval domains. This scheme provides an internal consistency check with RTM and $\mathrm{RTM}^{-1}$ calculations to establish a reliable link between radiometric error in the spectral radiance domain and retrieval error in the retrieval domain. It minimizes the validation uncertainty introduced by the different time and space sampling, which has been shown to be critically important in previous validation studies (Tobin et al. 2006, Pougatchev et al. 2009). The measurements are emulated with known geophysical parameters and identified error sources like instrument random noise and 'un-modelled' errors. The error and/or uncertainty of each retrieved parameter is given by ECAS analysis, providing detailed information on the quality of retrievals in reproducing the radiances 
corresponding to the measurements. The retrieval error budget estimation within this study is investigated in both radiance and retrieval domains.

ECAS is intended to estimate retrieval error through multi-step geophysical parameter retrievals and radiance simulations corresponding to an ensemble of observed radiances. Three major error sources are identified. The ill-posed retrieval error is from the nature of the mathematical limitation of this problem (i.e. the null-space error); it depends on the retrieval algorithm and the constraints used in the algorithm. A detailed analysis flowchart-A estimating 'un-modelled' radiance errors (i.e. its mean bias $E$ and STDE $\Sigma$ ) is given in figure 1. The notations in the figure are defined as radiances $\boldsymbol{Y}$, retrievals $\boldsymbol{X}$, instrument random noise $\delta$, radiance bias $\varepsilon^{\mathrm{Y}}$, and radiance $\operatorname{STDE} \sigma^{\mathrm{Y}}$. As shown in flowchart-A, 'un-modelled' radiance errors $[E, \Sigma]$ are estimated starting from an ensemble of observed (or measured) radiances $\boldsymbol{Y}_{\mathrm{o}}$ with its random noise $\delta$. The error components are defined as 'un-modelled', noise, and illposed retrieval by subscripts of $\mathrm{m}, \mathrm{n}$, and $\mathrm{r}$, respectively; and a total error is defined by subscript a.

The radiance discrepancy $\left[\varepsilon_{\mathrm{a}}^{\mathrm{Y}}, \sigma_{\mathrm{a}}^{\mathrm{Y}}\right]$ between observed radiances $\boldsymbol{Y}_{\mathrm{o}}$ and synthetic radiances $\boldsymbol{Y}_{\mathrm{s} 1}$ simulated from the retrievals $\boldsymbol{X}_{\mathrm{O}}$ is mainly contributed by the instrument random noise, 'un-modelled' errors, and retrieval-induced errors. We aim to estimate 'un-modelled' errors in the radiance domain with the observed radiances providing the instrument random noise. The retrieval process involved in the ECAS is over an ensemble of observations with a sample number large enough for statistical analysis. There are some additional errors generated through the retrieval process; they are defined as retrieval-induced errors (e.g. $\left[\varepsilon_{\mathrm{n}}^{\mathrm{Y}}, \sigma_{\mathrm{n}}^{\mathrm{Y}}\right]$ from the random noise), the statistical residual (or discrepancy) of two sets of simulated radiances (e.g. $\boldsymbol{Y}_{\mathrm{s} 2 \mathrm{u}}$ and $\boldsymbol{Y}_{\mathrm{s} 2 \mathrm{v}}$ ): one (e.g. $\boldsymbol{Y}_{\mathrm{s} 2 \mathrm{u}}$ ) is simulated with the geophysical parameters (e.g. $\left.\boldsymbol{X}_{\mathrm{s} 1}\right)$ retrieved from the original synthetic radiances (e.g. $\left.\boldsymbol{Y}_{\mathrm{s} 1}\right)$ and the other one (e.g. $\left.\boldsymbol{Y}_{\mathrm{s} 2 \mathrm{v}}\right)$ is

(a) Flowchart-A:

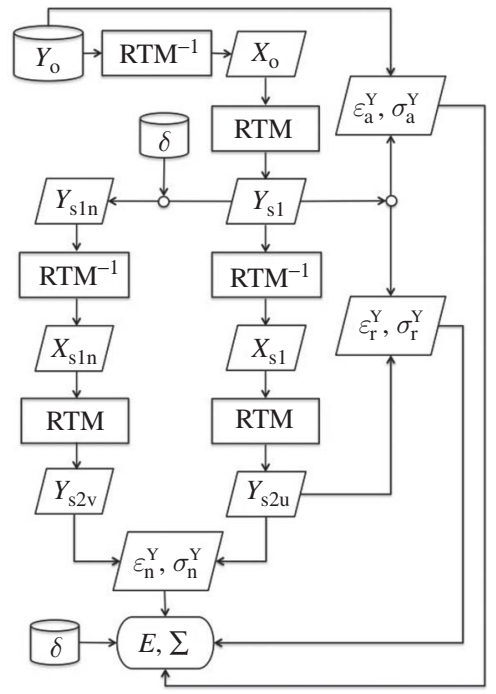

(b) Flowchart-B:

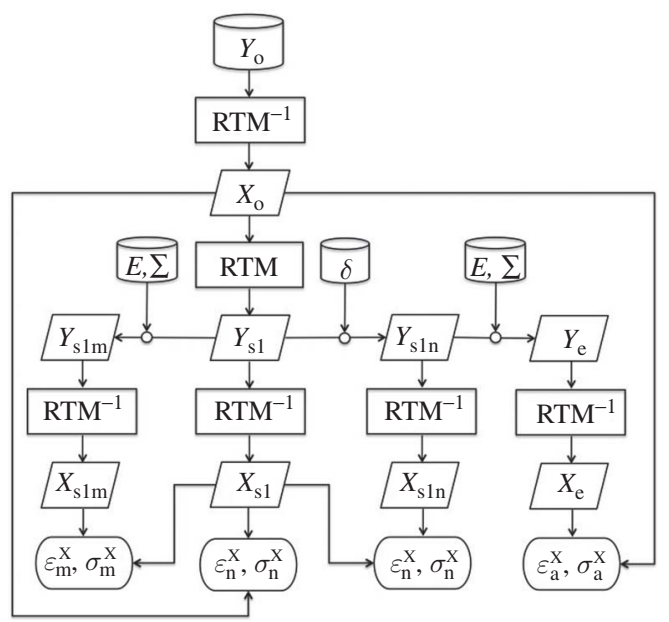

Figure 1. ECAS flowchart-A: The 'un-modelled' radiance errors $[E, \Sigma]$ are estimated starting with observed radiances $\boldsymbol{Y}_{\mathrm{o}}$ with instrument random noise $\delta$. ECAS Flowchart-B: The 'un-modelled' radiance errors $[E, \Sigma]$, instrument random noise $\delta$, and observed radiances $\boldsymbol{Y}_{\mathrm{o}}$ are used to estimate retrieval errors. 
simulated with the geophysical parameters (e.g. $\boldsymbol{X}_{\mathrm{sln}}$ ) retrieved from the error-addedon synthetic radiances (e.g. $\boldsymbol{Y}_{\mathrm{s} 1 \mathrm{n}}=\boldsymbol{Y}_{\mathrm{s} 1}+\delta$ ). This kind of error will be produced in the retrievals with error-free synthetic radiances also; in other words, the radiance fitting will never be perfect (i.e. zero residuals). For instance, in a perfect retrieval environment, the statistical residuals $\left[\varepsilon_{\mathrm{r}}^{\mathrm{Y}}, \sigma_{\mathrm{r}}^{\mathrm{Y}}\right]$ between $\boldsymbol{Y}_{\mathrm{s} 1}$ and $\boldsymbol{Y}_{\mathrm{s} 2 \mathrm{u}}$ in radiance domain would not be zeros.

In the ECAS analysis, the instrument random noise $\delta$ and 'un-modelled' errors $[E, \Sigma]$ are classified as the primary radiance errors and assumed to be independent, whereas the retrieval-induced errors $\left[\varepsilon_{\mathrm{r}}^{\mathrm{Y}}, \sigma_{\mathrm{r}}^{\mathrm{Y}}\right],\left[\varepsilon_{\mathrm{n}}^{\mathrm{Y}}, \sigma_{\mathrm{n}}^{\mathrm{Y}}\right]$, and $\left[\varepsilon_{\mathrm{m}}^{\mathrm{Y}}, \sigma_{\mathrm{m}}^{\mathrm{Y}}\right]$ are classified as secondary errors that are dependent on the primary radiance errors and the retrieval system but are much smaller than primary radiance errors. The total error is the sum of all the error components. The statistical residuals $\left[\varepsilon_{\mathrm{a}}^{\mathrm{Y}}, \sigma_{\mathrm{a}}^{\mathrm{Y}}\right]$ between the observed radiance $\boldsymbol{Y}_{\mathrm{o}}$ and simulated radiances $\boldsymbol{Y}_{\mathrm{s} 1}$ from the retrievals $\boldsymbol{X}_{\mathrm{o}}$ are then written as $\varepsilon_{\mathrm{a}}^{\mathrm{Y}}=E+\varepsilon_{\mathrm{m}}^{\mathrm{Y}}+\varepsilon_{\mathrm{r}}^{\mathrm{Y}}+\varepsilon_{\mathrm{n}}^{\mathrm{Y}}$ and $\left(\sigma_{\mathrm{a}}^{\mathrm{Y}}\right)^{2}=\delta^{2}+\Sigma^{2}+\left(\sigma_{\mathrm{m}}^{\mathrm{Y}}\right)^{2}+\left(\sigma_{\mathrm{r}}^{\mathrm{Y}}\right)^{2}+\left(\sigma_{\mathrm{n}}^{\mathrm{Y}}\right)^{2}$.

The secondary errors $\left[\varepsilon_{\mathrm{m}}^{\mathrm{Y}}, \sigma_{\mathrm{m}}^{\mathrm{Y}}\right]$ are retrieval-induced errors by 'un-modelled' errors $[E, \Sigma]$, which cannot be estimated through simulations with the unknown $[E, \Sigma]$. However, $\left[\varepsilon_{\mathrm{m}}^{\mathrm{Y}}, \sigma_{\mathrm{m}}^{\mathrm{Y}}\right]$ are small enough to be neglected in comparison with $[E, \Sigma]$. Also, $\varepsilon_{\mathrm{n}}^{\mathrm{Y}}$ is zero since it comes from the instrument random noise. Now we can estimate 'un-modelled' errors $[E, \Sigma]$ using $E \approx \varepsilon_{\mathrm{a}}^{\mathrm{Y}}-\varepsilon_{\mathrm{r}}^{\mathrm{Y}}$ and $\Sigma \approx\left[\left(\sigma_{\mathrm{a}}^{\mathrm{Y}}\right)^{2}-\delta^{2}-\left(\sigma_{\mathrm{r}}^{\mathrm{Y}}\right)^{2}-\right.$ $\left.\left(\sigma_{\mathrm{n}}^{\mathrm{Y}}\right)^{2}\right]^{1 / 2}$. It is noted that these 'un-modelled' errors depend on the observed radiances $\boldsymbol{Y}_{\mathrm{o}}$ taken in a specific environment. For example, using the measurements taken from a dusty environment will increase 'un-modelled' errors, as the current RTM does not have the capability to simulate dust.

Flowchart-B estimates the retrieval errors and is given in figure 1 as well. The notations in flowchart-B are defined as retrieval bias $\varepsilon^{\mathrm{X}}$ and STDE $\sigma^{\mathrm{X}}$ in addition to those defined in flowchart-A. The 'un-modelled' radiance errors $[E, \Sigma]$ from flowchart-A are now estimated and added on synthetic radiances $\boldsymbol{Y}_{\mathrm{s} 1}$ using a uniform random number generator with a random seed of $\Sigma$ and a bias $E$ to produce the radiances $\boldsymbol{Y}_{\mathrm{slm}}$. The retrievals $\boldsymbol{X}_{\mathrm{s} 1}$ and $\boldsymbol{X}_{\mathrm{s} 1 \mathrm{~m}}$ obtained from $\boldsymbol{Y}_{\mathrm{s} 1}$ and $\boldsymbol{Y}_{\mathrm{s} 1 \mathrm{~m}}$, respectively, are compared, and their statistical residuals $\left[\varepsilon_{\mathrm{m}}^{\mathrm{X}}, \sigma_{\mathrm{m}}^{\mathrm{X}}\right]$ are caused by 'un-modelled' errors $[E, \Sigma]$ assuming other errors in the retrieval system are the same in both $\boldsymbol{X}_{\mathrm{s} 1}$ and $\boldsymbol{X}_{\mathrm{s} 1 \mathrm{~m}}$ and cancel each other. A similar procedure is performed using instrument random noise instead of the 'un-modelled' errors to produce the retrieval errors $\left[\varepsilon_{\mathrm{n}}^{\mathrm{X}}, \sigma_{\mathrm{n}}^{\mathrm{X}}\right]$ caused by instrument random noise. The last component $\left[\varepsilon_{\mathrm{r}}^{\mathrm{X}}, \sigma_{\mathrm{r}}^{\mathrm{X}}\right]$ from the ill-posed problem itself is obtained by comparing the retrievals $\boldsymbol{X}_{\mathrm{o}}$ to $\boldsymbol{X}_{\mathrm{s} 1}$. This term depends on the retrieval system used to produce the retrievals. Since the difference between the observed radiance $\boldsymbol{Y}_{\mathrm{o}}$ and simulated radiance $\boldsymbol{Y}_{\mathrm{s} 1}$ is primarily due to the sum of instrument random noise and 'un-modelled' errors (i.e. consider primary radiance errors only), we can emulate observed-like radiances $\boldsymbol{Y}_{\mathrm{e}}$ by adding $\delta$ and $[E, \Sigma]$ to $\boldsymbol{Y}_{\mathrm{s} 1}$. The state vector $\boldsymbol{X}_{\mathrm{e}}$ retrieved from $\boldsymbol{Y}_{\mathrm{e}}$ is then compared with the $\boldsymbol{X}_{\mathrm{o}}$ to produce the total retrieval errors $\left[\varepsilon_{\mathrm{a}}^{\mathrm{X}}, \sigma_{\mathrm{a}}^{\mathrm{X}}\right]$. As shown in flowchart-B, the total error $\left[\varepsilon_{\mathrm{a}}^{\mathrm{X}}, \sigma_{\mathrm{a}}^{\mathrm{X}}\right]$ should be approximately equal to the sum of three error components: (1) an ill-posed retrieval error, (2) instrument random noise, and (3) 'un-modelled' errors. $\left[\varepsilon_{\mathrm{a}}^{\mathrm{X}}, \sigma_{\mathrm{a}}^{\mathrm{X}}\right]$ can be directly estimated or assumed by adding up its three components, $\varepsilon_{\mathrm{a}}^{\mathrm{X}} \approx \varepsilon_{\mathrm{r}}^{\mathrm{X}}+\varepsilon_{\mathrm{n}}^{\mathrm{X}}+\varepsilon_{\mathrm{m}}^{\mathrm{X}}$ and $\sigma_{\mathrm{a}}^{\mathrm{X}} \approx\left[\left(\sigma_{\mathrm{r}}^{\mathrm{X}}\right)^{2}+\left(\sigma_{\mathrm{n}}^{\mathrm{X}}\right)^{2}+\left(\sigma_{\mathrm{m}}^{\mathrm{X}}\right)^{2}\right]^{1 / 2}$.

\section{Analysis demonstration}

ECAS can be applied to any RTM and its inverse RTM ${ }^{-1}$. The RTM ${ }^{-1}$ (Zhou et al . 2007, 2009) used here only uses observed radiance and instrument random noise; 
no other 'truth' data from satellite or surface-based instruments or from numerical weather analysis/prediction models are utilized in assisting or constraining the retrieval products. The fast transmittance model used herein is a combination of the Stand-alone AIRS Radiative Transfer Algorithm (SARTA) Version 1.07 and the physically based cloud RTM based on the discrete ordinate radiative transfer (DISORT) calculations performed for a wide variety of cloud microphysical properties (Stamnes et al. 1988, Yang et al. 2001, Strow et al. 2003). The studies presented here only deal with clear-sky conditions; therefore, DISORT (or the cloud radiative transfer) model error is not estimated. An iterative 1-Dimensional Variational (1-D Var.) multivariable inversion using the minimum-information regularization method is used for obtaining the final retrieval. An all-season, global Empirical Orthogonal Function (EOF) regression database is used to obtain the initial profile for the 1-D Var. physical retrieval. A detailed retrieval algorithm has been described and demonstrated elsewhere (Zhou et al. 2009).

This analysis can be applied to any measurements; here we use IASI measurements, and the data used herein were collected during the JAIVEx campaign. Four granules, 19 April, 27 April, 29 April, and 4 May 2007, are used in the analysis. Each granule contains 5400 measurements covering the same area of the continental United States and the Gulf of Mexico. Only retrievals identified as 'clear-sky' measurements are used to represent error budget estimations under 'clear-sky' conditions. A detailed case study of 29 April 2007 can be found elsewhere (Zhou et al. 2009); it is worthwhile to note that the same retrieval algorithm is used herein. Spectral radiance discrepancy between RTM calculation and observed radiance is derived. Demonstrations shown here are from a 19 April 2007 granule taken from above the continental US, using 3398 'clear' cases out of a total of 5400 observations. Radiance discrepancy is calculated in both radiance and brightness temperature units but plotted in brightness temperature for clarity.

Following flowchart-A, a total radiance bias $\varepsilon_{\mathrm{a}}^{\mathrm{Y}}$, derived from $\boldsymbol{Y}_{\mathrm{s} 1}$ and $\boldsymbol{Y}_{\mathrm{o}}$, together with retrieval-induced radiance bias $\varepsilon_{\mathrm{r}}^{\mathrm{Y}}$ are plotted in figures $2(a)$ and $(b)$, respectively. They are used to derive 'un-modelled' radiance bias $E$, plotted in figure $2(c)$. To estimate 'un-modelled' radiance STDE $\Sigma$, a total radiance STDE $\sigma_{\mathrm{a}}^{\mathrm{Y}}$ plotted in figure 2(d), derived from $\boldsymbol{Y}_{\mathrm{s} 1}$ and $\boldsymbol{Y}_{\mathrm{o}}$, is used together with $\sigma_{\mathrm{r}}^{\mathrm{Y}}, \sigma_{\mathrm{n}}^{\mathrm{Y}}$, and an instrument random noise $\delta$ of this dataset. Both $\sigma_{\mathrm{r}}^{\mathrm{Y}}$ and $\sigma_{\mathrm{n}}^{\mathrm{Y}}$, plotted in figure 2(e), can be estimated through simulations (see flowchart-A). It is noticed that estimated $\Sigma$, plotted in figure $2(f)$, at some wavenumbers is set at zero, which is an explainable artefact due to the uncertainty of the random noise of the measurements.

Now the 'un-modelled' radiance errors are estimated. Following ECAS flowchart-B, the discrepancy between $\boldsymbol{X}_{\mathrm{o}}$ and $\boldsymbol{X}_{\mathrm{e}}$ (i.e. a total retrieval error $\left[\varepsilon_{\mathrm{a}}^{\mathrm{X}}, \sigma_{\mathrm{a}}^{\mathrm{X}}\right]$ ) is also assumed to be the sum of individually estimated error components. Two approaches for the total retrieval error estimation have given nearly the same results. We use the JAIVEx IASI dataset of 29 April 2007, the case study presented in our previous publication (Zhou et al. 2009), to demonstrate total retrieval error estimation. A cross section of IASI data samples (see figure 3) shows the surface skin temperatures and vertical cross sections of atmospheric temperature and water vapour (WV) profiles. These parameters are a subset of geophysical state vector $\boldsymbol{X}_{\mathrm{e}}$ retrieved from $\boldsymbol{Y}_{\mathrm{e}}$. The total retrieval error is calculated by comparing $\boldsymbol{X}_{\mathrm{e}}$ with $\boldsymbol{X}_{\mathrm{o}} ; \boldsymbol{X}_{\mathrm{o}}$ serves as the 'truth' and is used to generate $\boldsymbol{Y}_{\mathrm{e}}$ using instrument random noise and 'un-modelled' errors. It is noted that the total retrieval error (i.e. $\boldsymbol{X}_{\mathrm{e}}-\boldsymbol{X}_{\mathrm{o}}$ ) plotted in figure 3 is not an absolute retrieval error of each measurement but rather in a statistical form (i.e. bias and STDE) as the radiance error assigned to the synthetic radiances is random number 
(a)

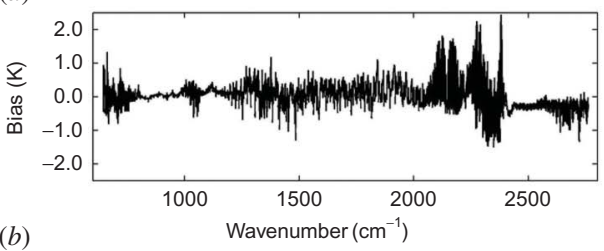

(b)

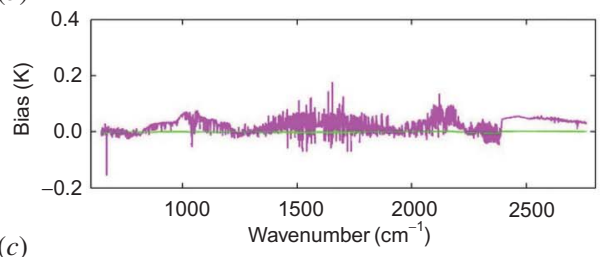

(c)

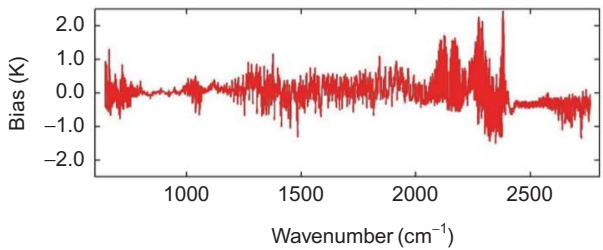

(d)

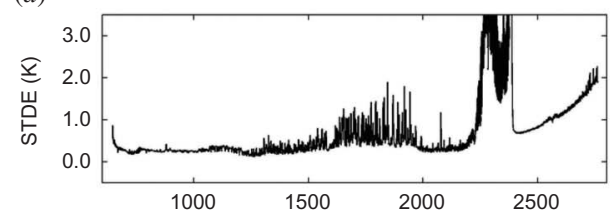

(e)

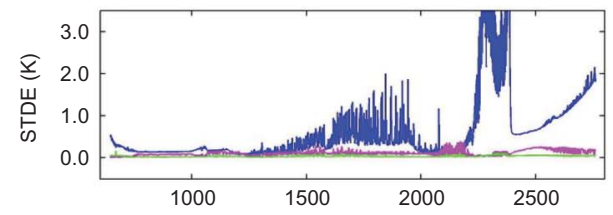

$(f)$

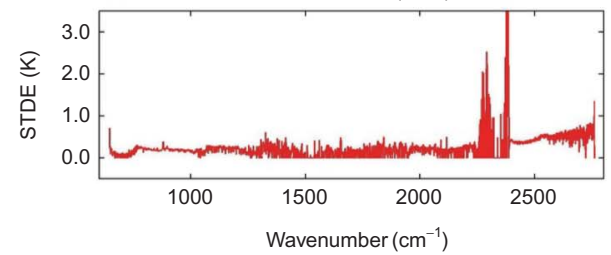

Figure 2. Left panel in brightness temperature $(\mathrm{K}):(a)$ Total estimated radiance bias $\varepsilon_{\mathrm{a}}^{\mathrm{Y}},(b)$ the retrieval-induced spectral bias $\varepsilon_{\mathrm{n}}^{\mathrm{Y}}$ introduced by random noise (in green) and ill-posed retrieval $\varepsilon_{\mathrm{r}}^{\mathrm{Y}}$ (in magenta), and $(c)$ estimated 'un-modelled' radiance bias $E$. Right panel in brightness temperature $(\mathrm{K}):(d)$ Total estimated radiance STDE $\sigma_{\mathrm{a}}^{\mathrm{Y}},(e)$ instrument random noise $\delta$ (in blue), and the retrieval-induced spectral STDE $\sigma_{\mathrm{n}}^{\mathrm{Y}}$ introduced by random noise (in green) and ill-posed retrieval $\sigma_{\mathrm{r}}^{\mathrm{Y}}$ (in magenta), and $(f)$ estimated 'un-modelled' radiance STDE $\Sigma$.

(a)

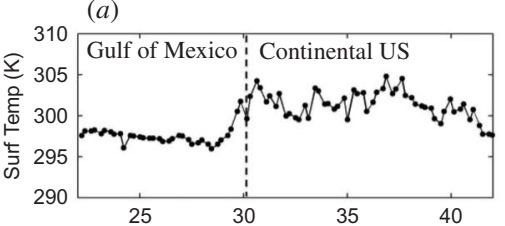

(c)

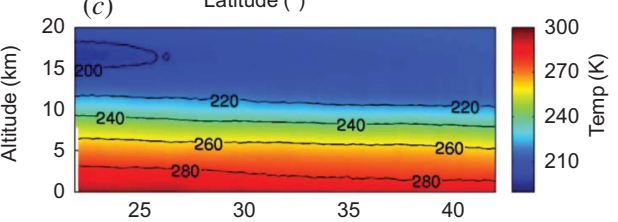

(e)

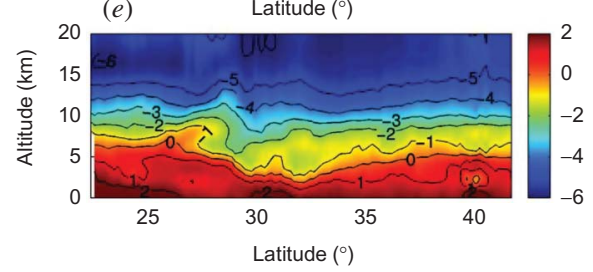

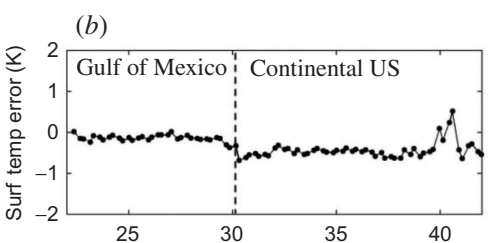
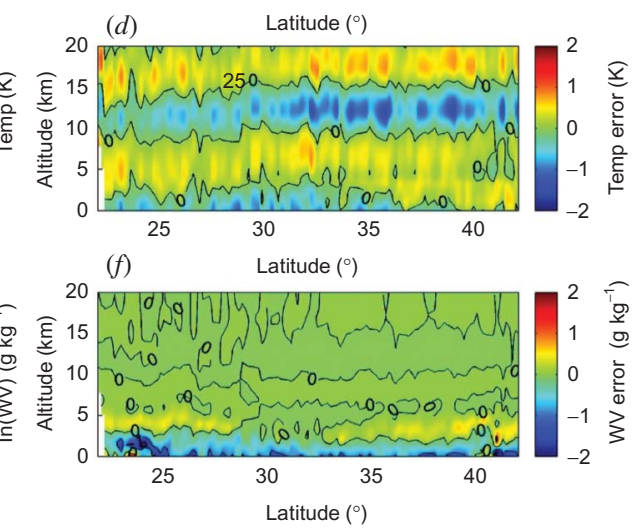

Figure 3. (a)-(b) Surface skin temperature and its error, respectively, $(c)-(d)$ vertical cross section of atmospheric temperature and its error, respectively, and $(e)-(f)$ vertical cross section of atmospheric water vapour (logarithm scale) and its error (linear scale), respectively. 
(a)

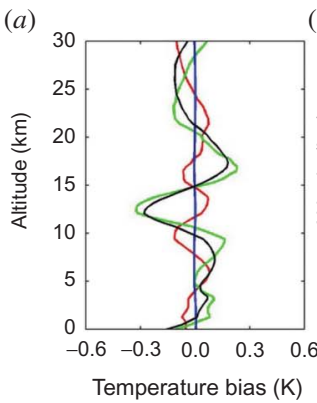

(b)

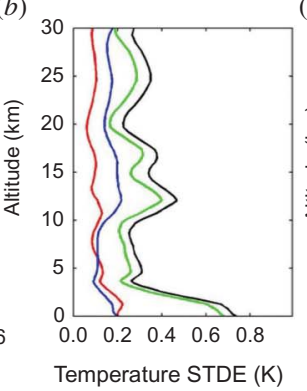

(c)

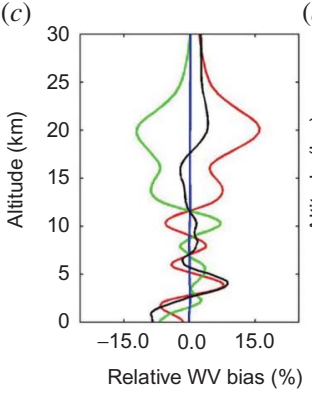

(d)

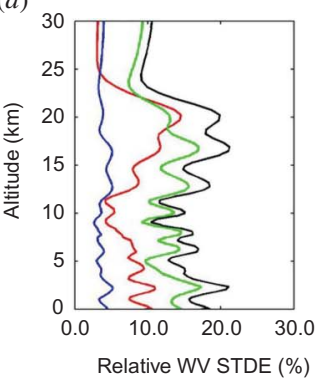

Figure 4. (a) Bias and (b) STDE for temperature profile error budget estimation; (c) bias and $(d)$ STDE for water vapour profile error budget estimation in a relative value (percentage) of water vapour mixing ratio in $\left(\mathrm{g} \mathrm{kg}^{-1}\right)$. Retrieval errors contributed by ill-posed retrieval, instrument random noise, and 'un-modelled' radiance errors are plotted in green, blue, and red, respectively, and total retrieval errors are plotted in black.

generated. A large, statistically representative dataset is used to compute retrieval errors in terms of the bias and STDE, representing retrieval accuracy in a general sense, with the retrieval algorithm used for this analysis under similar thermodynamic conditions.

The temperature and moisture profile errors are plotted in figure 4 (WV in a relative form to their profiles). Retrieval error estimates shown in figure 4 are derived from four JAIVEx granules over the continental United States and the Gulf of Mexico using 11,871 identified 'clear' cases out of a total 21,600 observations. Retrieval errors of surface parameters (e.g. surface skin temperature and emissivity) from the same dataset are computed in the same manner. For surface skin temperature $T_{\mathrm{s}}$, the errors contributed by different sources $\left[\varepsilon_{\mathrm{n}}^{\mathrm{Ts}}, \sigma_{\mathrm{n}}^{\mathrm{Ts}}\right],\left[\varepsilon_{\mathrm{r}}^{\mathrm{Ts}}, \sigma_{\mathrm{r}}^{\mathrm{Ts}}\right]$, and $\left[\varepsilon_{\mathrm{m}}^{\mathrm{Ts}}, \sigma_{\mathrm{m}}^{\mathrm{Ts}}\right]$ are $[0.00 \mathrm{~K}, 0.153 \mathrm{~K}]$, $[-0.093 \mathrm{~K}, 0.276 \mathrm{~K}]$, and $[-0.127 \mathrm{~K}, 0.131 \mathrm{~K}]$, respectively. The total $T_{\mathrm{s}}$ error $\left[\varepsilon_{\mathrm{a}}^{\mathrm{Ts}}, \sigma_{\mathrm{a}}^{\mathrm{Ts}}\right]$ is estimated as $[-0.220 \mathrm{~K}, 0.342 \mathrm{~K}]$. The total $T_{\mathrm{s}}$ error for land and water is estimated to be $[-0.270 \mathrm{~K}, 0.349 \mathrm{~K}]$ and $[-0.134 \mathrm{~K}, 0.362 \mathrm{~K}]$, respectively. It is noted that the error estimation for other retrieved parameters is not illustrated here but performed in the same manner. Estimated retrieval errors herein for JAIVEx data are reasonable, although the STDE of atmospheric temperature seems smaller than the previous estimation using radiosonde measurements without considering spatial-temporal differences (Zhou et al. 2009). With the consideration of spatial-temporal differences using VAM (Pougatchev et al. 2009), IASI temperature retrieval STDE is expected to be $\sim 0.4 \mathrm{~K}$ at $9 \mathrm{~km}$ and below. That is similar to the ECAS estimation shown in figure $4(b)$.

\section{Discussion and summary}

Estimated 'un-modelled' radiance error can be different from time to time and depend on atmospheric conditions (e.g. aerosol, dust, and some trace species not modelled in current RTM). Estimated 'un-modelled' radiance error can be used to construct the error covariance matrix needed in most conventional retrieval method. The advantage of this analysis is that we can effectively estimate the error budget from the RTM and $\mathrm{RTM}^{-1}$ systems employed in both the radiance and retrieval domains. Since the analysis is within radiance simulation and retrieval starts with observed radiance spectra, the horizontal footprint size of a retrieved profile obtained from its 
associated-observed spectrum is the same as the one it compares with and produces the final retrieval error. The retrieval errors resulting from this ill-posed retrieval system, $\left[\varepsilon_{\mathrm{r}}^{\mathrm{X}}, \sigma_{\mathrm{r}}^{\mathrm{X}}\right.$, are computed from retrievals $\boldsymbol{X}_{\mathrm{o}}$ and $\boldsymbol{X}_{\mathrm{s} 1}$, with $\boldsymbol{X}_{\mathrm{o}}$ serving as the true state vector. These retrievals, produced with the same retrieval system and very similar radiances (i.e. atmospheric and surface conditions), have a very similar vertical resolution. There is no time and space difference between the profiles used for comparison, which provides the critical advantage of limiting the uncertainty caused by a different time and space of the 'truth' in conventional retrieval validation or error estimation. The ECAS can provide retrieval errors on the parameters, such as land surface skin temperature and emissivity, normally being very difficult to validate using the previous conventional method.

On the other hand, the ECAS contains an ill-posed problem that may cause some concern. One may argue that $\boldsymbol{X}_{\mathrm{o}}$ and $\boldsymbol{X}_{\mathrm{s} 1}$ have a similar retrieval oscillation or a similar vertical resolution since $\boldsymbol{X}_{\mathrm{o}}$ is retrieved from $\boldsymbol{Y}_{\mathrm{o}}$ using the same $\mathrm{RTM}^{-1}$. Nevertheless, if the same retrieval error, independent on its vertical resolution, would exist in both $\boldsymbol{X}_{\mathrm{o}}$ and $\boldsymbol{X}_{\mathrm{s} 1}$, then the ill-posed retrieval errors could be underestimated. The retrieval parameters and their errors compensate to a certain degree among themselves, although constraints are used in the retrieval to minimize such cross talk among retrieved parameters. For example, the retrieval errors estimated herein for surface skin temperature and emissivity spectra could compensate each other to satisfy a minimal radiance fitting in the retrieval process. In addition, the error estimation is meaningful only if that parameter is retrieval sensitive. For instance, error for the moisture profile above the tropopause $(\sim 18 \mathrm{~km})$, shown in figure 4 , is not meaningful because the retrieved moisture above the tropopause is not sensitive to observed radiances. It is also noted that the 1-D Var. retrieval presented herein might be suboptimal since an estimated error is used for all retrievals. In other words, retrievals from observed radiances may contain errors slightly different from the errors in the retrievals obtained from retrieval-simulated radiances. Nevertheless, we believe that these effects are small enough to be ignored.

It is our intention to not only give an estimated error profile, but to introduce a new approach for general ultraspectral sounding retrieval error budget estimation in conjunction with an associated spectral radiance error. This scheme can be used together with other previous validation methodologies to give a more definitive answer on the error and/or uncertainty of retrieved products from ultraspectral radiances observed by current and future satellites.

\section{Acknowledgements}

IASI L1C data are provided by the Unified Meteorological Archival and Retrieval Facility (UMARF) of EUMETSAT. The fast cloud radiative transfer model was provided by Dr. Ping Yang of Texas A\&M University. This research is supported by NASA Langley Research Center and NASA Headquarters. We would like to acknowledge support from NASA Headquarters Research Division Director Dr. Jack Kaye, and to extend our appreciation to the anonymous reviewers for their suggestions.

\section{References}

Hilton, F., Armante, R., August, T., Barnet, C., Bouchard, A., Camy-Peyret, C., Capelle, V., Clarisse, L., Clerbaux, C., Coheur, P.-F., Collard, A., Crevoisier, C., Dufour, G., Edwards, D., Faijan, F., Fourrié, N., Gambacorta, A., Goldberg, M., Guidard, V., Hurtmans, D., Illingworth, S., Jacquinet-Husson, 
N., Kerzenmacher, T., Klaes, D., Lavanant, L., Masiello, G., Matricardi, M., Mcnally, A., Newman, S., Pavelin, E., Payan, S., Péquignot, E., Peyridieu, S., Phulpin, T., Remedios, J., Schlüssel, P., Serio, C., Strow, L., Stubenrauch, C., Taylor, J., Tobin, D., Wolf, W. and Zhou, D., 2012, Hyperspectral earth observation from IASI: five years of accomplishments. Bulletin of the American Meteorological Society, 93, pp. 347-370.

Klaes, D.K., Cohen, M., Buhler, Y., Schlüssel, P., Munro, R., Luntama, J.-P., Von Engeln, A., Clerigh, E.Ó., Bonekamp, H., Ackermann, J. and Schmetz, J., 2007, An introduction to the EUMETSAT polar system. Bulletin of the American Meteorological Society, 88, pp. 1085-1096.

Larar, A.M., Smith, W.L., Zhou, D.K., Liu, X., Revercomb, H.E., Taylor, J.P., Newman, S.M. and SCHLÜSSEL, P., 2010, IASI spectral radiance validation inter-comparisons: case study assessment from the JAIVEx field campaign. Atmospheric Chemistry and Physics, 10, pp. 441-430.

Pougatchev, N., August, T., Calbet, X., Hultberg, T., Oduleye, O., Schlüssel, P., Stiller, B., Germain, S.K. and Bingham, G., 2009, IASI temperature and water vapor retrievals - error assessment and validation. Atmospheric Chemistry and Physics, 9, pp. 6453-6458.

Rodgers, C.D., 2000, Inverse Methods for Atmospheric Sounding: Theory and Practice, pp. 1-238 (Singapore: World Scientific).

Stamnes, K., Tsay, S.-C., Wiscombe, W. and Jayaweera, K., 1988, Numerically stable algorithm for discrete-ordinate-method radiative transfer in multiple scattering and emitting media. Applied Optics, 27, pp. 2502-2509.

Strow, L.L., Hannon, S.E., De Souza-Machado, S., Motteler, H.E. and Tobin, D., 2003, An overview of the AIRS radiative transfer model. IEEE Transactions on Geoscience Remote Sensing, 41, pp. 303-313.

Tobin, D.C., Revercomb, H.E., Knuteson, R.O., Lesht, B.M., Strow, L.L., Hannon, S.E., Feltz, W.F., Moy, L.A., Fetzer, E.J. and Cress, T.S., 2006, Atmospheric radiation measurement site atmospheric state best estimates for atmospheric infrared sounder temperature and water vapor retrieval validation. Journal of Geophysical Research, 111, D09S14, doi:10.1029/2005JD006103.

Yang, P., Gao, B.C., Baum, B.A., Hu, Y., Wiscombe, W.J., Tsay, S.-C., Winker, D.M. and NAsiri, S.L., 2001, Radiative properties of cirrus clouds in the infrared $(8-13 \mu \mathrm{m})$ spectral region. Journal of Quantitative Spectroscopy \& Radiative Transfer, 70, pp. 473-504.

Zhou, D.K., Smith, W.L., Larar, A.M., Liu, X., Taylor, J.P., Schlüssel, P., Strow, L.L. and MANGo, S.A., 2009, All weather IASI single field-of-view retrievals: case study validation with JAIVEx data. Atmospheric Chemistry and Physics, 9, pp. 2241-2255.

Zhou, D.K., Smith, Sr., W.L., Liu, X., Larar, A.M., Mango, S.A. and Huang, H.-L., 2007, Physically retrieving cloud and thermodynamic parameters from ultraspectral IR measurements. Journal of the Atmospheric Sciences, 64, pp. 969-982. 